\title{
The (pro)renin receptor: a novel biomarker and potential therapeutic target for various cancers
}

\author{
Juan Wang ${ }^{1,2^{*}} \mathbb{D}$, Akira Nishiyama ${ }^{3}$, Makoto Matsuyama ${ }^{4}$, Zhiyu Wang $^{5}$ and Ying Yuan ${ }^{1,2^{*}}$
}

\begin{abstract}
Background: The (pro) renin receptor ((P)RR) plays important roles in various pathways, such as the Wnt/ $\beta$-catenin, renin-angiotensin system (RAS), MAPK/ERK and PI3K/AKT/mTOR pathways, that are involved in a wide range of physiological and pathological processes incorporating the tumorigenesis. However, our knowledge about (P) RR was mostly limited to its roles in cardiovascular and renal physiological functions and diseases. In the past 5 years, however, compelling evidence has revealed that $(P) R R$ is aberrantly expressed in and contributes to the development of various cancers by different means. For instance, (P) RR was recently demonstrated to induce the oncogenesis of pancreatic, colorectal and brain cancers via the Wnt signaling, while promote the endometrial cancer and glioblastoma through the RAS.

Methods: Combining with the deep analysis of big data from The Cancer Genome Atlas (TCGA) and Genotype-Tissue Expression (GTEx) databases, this review updates and summarizes the recent studies about the newly recognized roles of (P) RR in the pathophysiological processes of cancer development and its detailed functions through related pathways, as well as the novel research progress of (P) RR in related fields including the development and application of soluble (P) RR detection kit and monoclonal (P) RR antibody.
\end{abstract}

Results: This review provides an overview of the essential roles of (P) RR in the tumorigenesis and progression of various cancers and offers a translational outlook for the future research and clinical practices.

Conclusion: (P) RR in the tumor tissues and/or body fluids of patients may be a novel and promising biomarker and potential therapeutic target for diagnosis, treatment and prognosis prediction in various cancers.

Keywords: (Pro) renin receptor, Cancer, Wnt/B-catenin signaling pathway, RAS, Biomarker, Cancer targeted therapy

\section{Background}

The (pro) renin receptor $((\mathrm{P}) \mathrm{RR})$ is a single transmembrane protein consisting of 350 amino acids and encoded by the ATP6AP2 gene located on the $\mathrm{X}$ chromosome. (P) $\mathrm{RR}$ is widely expressed in the brain, heart, liver, pancreas, placenta and kidney. Initially, our knowledge about this receptor was limited to its effects on enhancing the tissue

\footnotetext{
* Correspondence: wangjuan2@zju.edu.cn; yuanying1999@zju.edu.cn 'Department of Medical Oncology, The Second Affiliated Hospital of Zhejiang University School of Medicine, Hangzhou, China

Full list of author information is available at the end of the article
}

renin-angiotensin system (RAS) via binding to its ligands renin and/or prorenin and inducing the activation of intracellular MAPK/ERK (MAPK and ERK are different names of a same protein molecule) pathway (also known as the Ras-Raf-MEK-ERK pathway) independent of the RAS, thus exerting pivotal effects in cardiovascular and renal functions and diseases [1]. (P) RR was later revealed to participate in a wide range of physiological and pathological processes and pathways such as vacuolar $\mathrm{H}+$ ATPase (V-ATPase) function [2] and the $\mathrm{Wnt} / \beta$-catenin signaling pathway [3]. Interestingly, accumulating studies

(c) The Author(s). 2020 Open Access This article is licensed under a Creative Commons Attribution 4.0 International License, which permits use, sharing, adaptation, distribution and reproduction in any medium or format, as long as you give appropriate credit to the original author(s) and the source, provide a link to the Creative Commons licence, and indicate if changes were made. The images or other third party material in this article are included in the article's Creative Commons licence, unless indicated otherwise in a credit line to the material. If material is not included in the article's Creative Commons licence and your intended use is not permitted by statutory regulation or exceeds the permitted use, you will need to obtain permission directly from the copyright holder. To view a copy of this licence, visit http://creativecommons.org/licenses/by/4.0/ The Creative Commons Public Domain Dedication waiver (http://creativecommons.org/publicdomain/zero/1.0/) applies to the data made available in this article, unless otherwise stated in a credit line to the data. 
indicate that the RAS [4], MAPK/ERK [5-7], V-ATPaserelated [8] and Wnt/ $\beta$-catenin signaling [9] pathways contribute to cancer initiation and progression through different means. Considering these connections, scientists asked the following question "Does (P) RR play a role in cancer development through one or several of these mechanisms?" In the past 5 years, compelling evidence has revealed that $(\mathrm{P}) \mathrm{RR}$ expression is significantly increased in many human cancers and benign tumors, such as colorectal cancer (CRC) [10], pancreatic ductal adenocarcinoma (PDAC) [11, 12], glioma [13], breast carcinoma [14] and aldosterone-producing adenoma [15], in comparison to that in normal tissues. Consistently, we have compared the levels of ATP6AP2 transcripts in tumor tissues of different cancers and corresponding matched normal tissues, based on the data provided in The Cancer Genome Atlas (TCGA) and Genotype-Tissue Expression (GTEx) databases, and found that obviously higher ATP6AP2 expression widely exists in various cancers, especially in the lymphoid neoplasm diffuse large B-cell Lymphoma (DLBC), kidney renal clear cell carcinoma (KIRC), pancreatic adenocarcinoma (PAAD), stomach adenocarcinoma (STAD), testicular germ cell tumors (TGCT) and thymoma (THYM) (Fig. 1). This review further summarizes the current knowledge of (P) RR along with the related mechanisms and discusses its translational potential in the context of cancer development, diagnosis, severity evaluation, treatment and prognosis prediction.

\section{Molecular structure}

(P) RR is composed of an extracellular domain containing the $\mathrm{N}$-terminal region, a transmembrane domain and a cytoplasmic domain containing the C-terminal region. Biologically, the full-length (P) RR (FL(P)RR) protein can be proteolytically cleaved by furin [16] or ADAM19 [17] in the Golgi apparatus to generate a

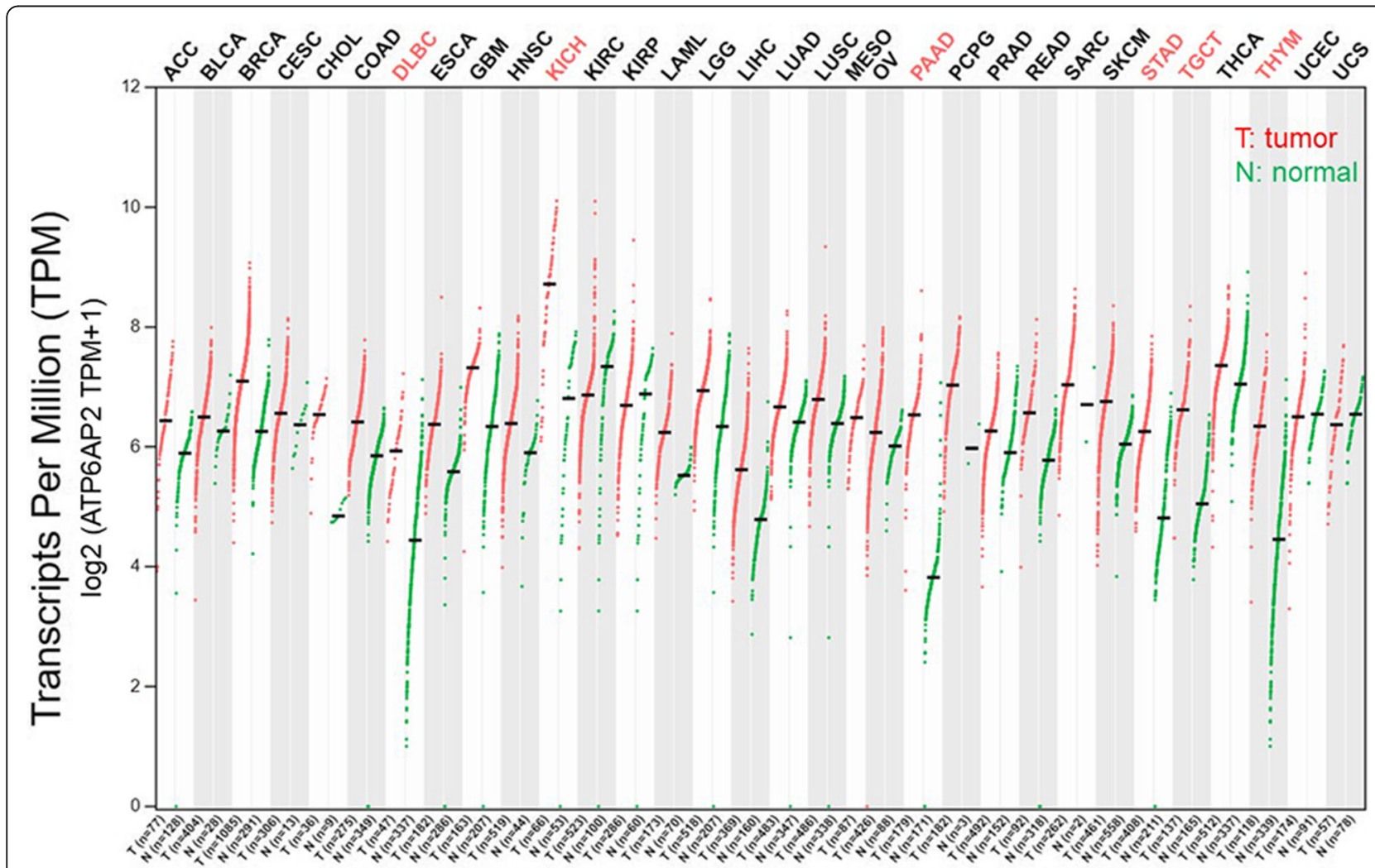

Fig. 1 Levels of transcripts of ATP6AP2 ((P) RR encoding gene) in pan-cancers and corresponding normal tissues. Obviously higher ATP6AP2 expression was found widely exists in tumor (T) tissues of various cancers compared to the corresponding normal (N) tissues, especially in the lymphoid neoplasm diffuse large B-cell Lymphoma (DLBC), kidney renal clear cell carcinoma (KRRC), pancreatic adenocarcinoma (PAAD), stomach adenocarcinoma (STAD), testicular germ cell tumors (TGCT) and thymoma (THYM). T: tumor tissue; N: normal tissue; n: number; ACC: adrenocortical carcinoma; BLCA: bladder urothelial carcinoma; BRCA: breast invasive carcinoma; CESC: cervical squamous cell carcinoma and endocenvical adenocarcinoma; CHOL: cholangiocarcinoma; COAD: colon adenocarcinoma; DLBC: lymphoid neoplasm diffuse large B-cell lymphoma; ESCA: esophageal carcinoma; GBM: glioblastoma multiforme; HNSC: head and neck squamous cell carcinoma; KICH: kidney chromophobe; KIRC: kidney renal clear cell carcinoma; KIRP: kidney renal papillary cell carcinoma; LAML: acute myeloid leukemia; LGG: brain lower grade glioma; LIHC: liver hepatocellular carcinoma; LUAD: lung adenocarcinoma; LUSC: lung squamous cell carcinoma; MESO: mesothelioma; OV: ovarian serous cystadenocarcinoma; PAAD: pancreatic adenocarcinoma; PCPG: Pheochromocytoma and Paraganglioma; PRAD: prostate adenocarcinoma; READ: rectum adenocarcinoma; SARC: sarcoma; SKCM: skin cutaneous melanoma; STAD: stomach adenocarcinoma; TGCT: testicular germ cell tumors; THCA: thyroid carcinoma; THYM: thymoma; UCEC: uterine corpus endometrial carcinoma; UCS: uterine carcinosarcoma 
truncated soluble form containing the $\mathrm{N}$-terminal region (soluble (P)RR; s(P)RR) [16] and a truncated transmembrane form containing the C-terminal region (M8-9 fragment) [18] (Fig. 2). $\mathrm{s}(\mathrm{P}) \mathrm{RR}$ is then secreted into body fluids.

\section{(P) RR and cancer-related pathways or factors The Wnt/ $\beta$-catenin signaling pathway}

The Wnt/ $\beta$-catenin pathway is well known for its essential contributions to the initiation of various cancers such as colorectal [19], gastric [20], prostate [21], breast [22] and adrenocortical [23] cancer. Without the binding of Wnt ligands (Wnts) to the Wnt receptor complex (initially thought to be composed only of Frizzled and LRP5/6), several proteins including APC, Axin and GSK3, usually combine and form the 'destruction complex' to cause $\beta$ catenin inactivation, ubiquitination and degradation. The binding of Wnts to the Wnt receptor complex leads to phosphorylation of LRP6, internalization of the complex as an LRP6 signalosome and following disruption of the

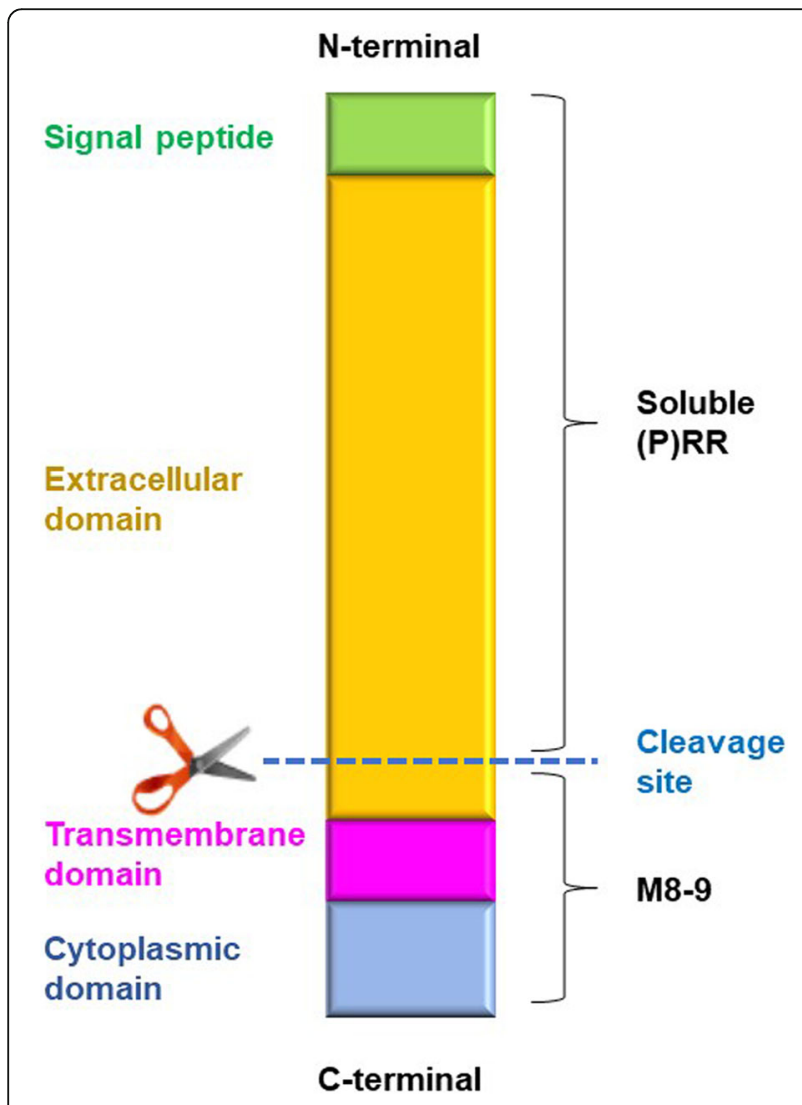

Fig. 2 Structure of (P)RR. The (pro) renin receptor ((P)RR) is a single transmembrane protein composed of an extracellular domain containing the N-terminal region, a transmembrane domain and a cytoplasmic domain containing the C-terminal region. The full-length (P) RR (FL(P)RR) protein can be cleaved by furin or ADAM19 into a truncated soluble form containing the $\mathrm{N}$-terminal region (soluble $(P) R R ; s(P) R R$ ) and a truncated transmembrane form containing the C-terminal region (M8-9 fragment) destruction complex, thus protecting $\beta$-catenin from inactivation and degradation. Active $\beta$-catenin trans-locates to the nucleus and binds the transcription factor TCF/LEF to enhance the expression of target oncogenes such as $c$ $M y c, A X I N 2$ and CCND1 (which encodes Cyclin D1) [2426]. The first link between $(\mathrm{P}) \mathrm{RR}$ and the $\mathrm{Wnt} / \beta$-catenin pathway was clarified by Cruciat et al. [3], who indicated that $(\mathrm{P}) \mathrm{RR}$ is an important component of the Wnt receptor complex and acts as an adaptor between LRP6 and the V-ATPase independent of the RAS, thus facilitating the binding of Wnts to the Wnt receptor complex [3]. Based on this evidence, further studies convincingly revealed that (P) RR promotes pancreatic [11], brain [13] and colorectal [10] cancers through the Wnt/ $\beta$-catenin pathway. Interestingly, research also suggests that $(\mathrm{P}) \mathrm{RR}$ not only serves as a membrane adaptor protein but also exists in the cytoplasm and positively affects the protein expression level of Wnt2 in glioma cells [13] as well as that of Wnt3 and total LRP6 in CRC cells [10]. In summary, (P) RR is a potential novel onco-protein in $\mathrm{Wnt} / \beta$-catenin pathway-related oncogenesis (Fig. 3).

\section{The RAS pathway}

The most well-known function of (P) RR is in the RAS. The binding of renin or its precursor prorenin to (P) RR enhances the enzymatic activity of these molecules, which further facilitates the catalysis of angiotensinogen (AGT) to angiotensin (Ang) I. Then, Ang I is acted on by angiotensin-converting enzyme (ACE) to produce Ang II, which triggers Ang II receptor-mediated signal transduction, leading to elevated tissue RAS activity [4]. Accumulating evidence suggests that the RAS affects cancer cell proliferation, apoptosis inhibition, migration, and invasion, as well as metastasis [27]. The increased activation of the RAS through both Ang II/Ang II receptor (AGTR) 1 and (pro)renin/(P) RR promotes cancer development by stimulating the downstream factors that contribute to oncogenesis [28]. Interestingly, transforming growth factor (TGF) $\beta$, which is crucial for epithelial-tomesenchymal transition (EMT) of metastatic cancer cells and is positively associated with RAS activity, is commonly upregulated in tumor tissues [29], which suggesting that $(\mathrm{P})$ RR might promote cancer metastasis through RAS-mediated TGF $\beta$ activation. Therefore, (P) RR may promote cancer initiation and progression via the RAS (Fig. 3).

\section{The MAPK/ERK and PI3K/AKT/mTOR pathways}

The binding of renin or prorenin to (P) RR activates MAPK/ ERK signaling and up-regulates extracellular signal-regulated kinase 1/2 (ERK1/2) in several types of cells, such as collecting duct cells, monocytes, mesangial cells, and neurons [30]. ERK1/2 activation enhances cell proliferation and induces TGF- $\beta$ generation $[6,7]$, which mediates the pathogenesis and metastasis of cancer. Additionally, (P) RR induces reactive oxygen species (ROS) formation, which is independent of 


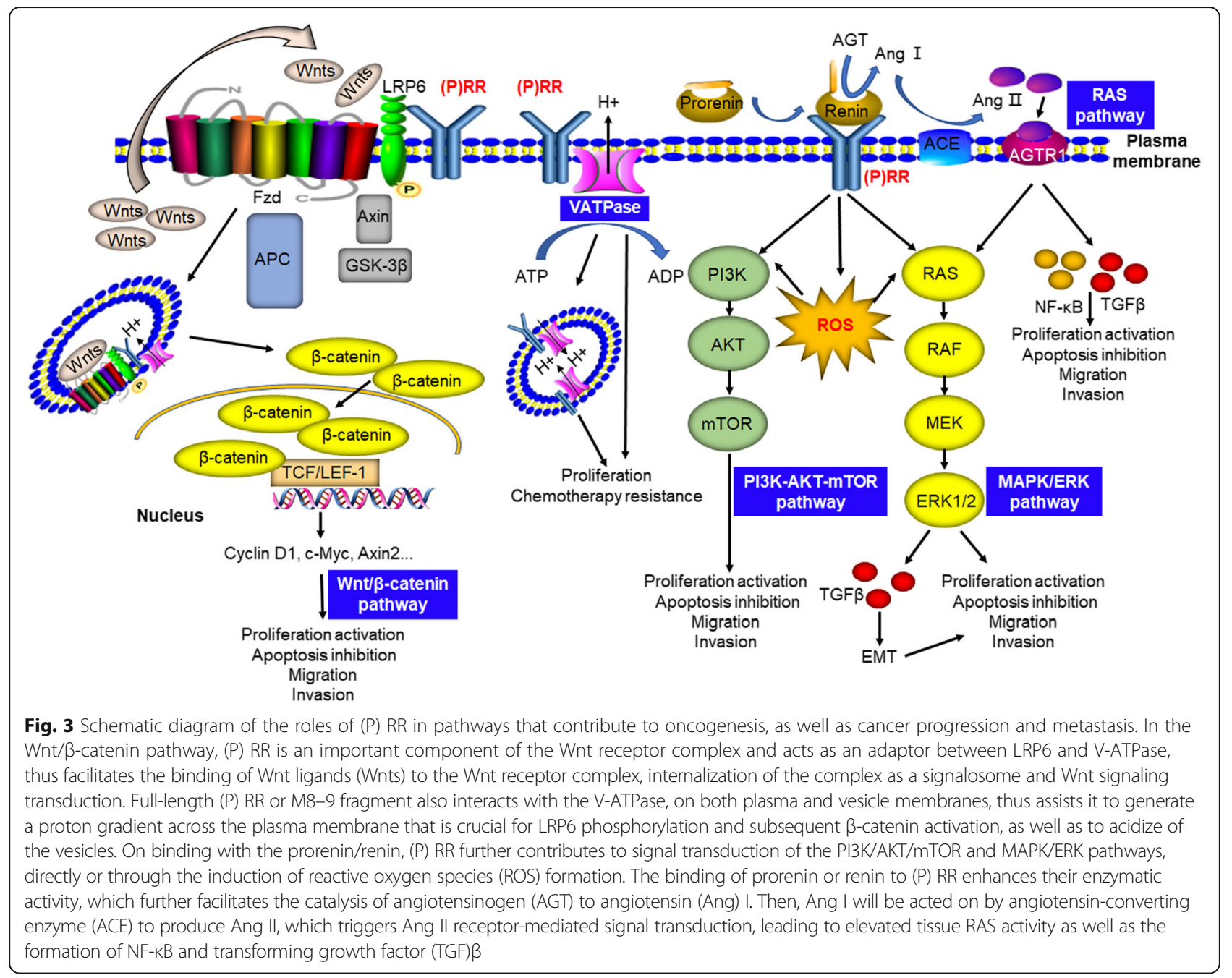

Ang II, thus further contributing to MAPK/ERK and PI3K/ AKT/mTOR signal transduction [31]. Consistent with these observations, Arundhathi et al. [32] investigated the function of (P) RR in the biological activities of the human pancreatic cancer cell lines Panc-1 and ASPC and found that (P) RR exerts a cancer-promoting effect by enhancing activity in the MAPK/ERK and PI3K/AKT/mTOR signaling pathways. In particular, the data from this group showed that $(\mathrm{P}) \mathrm{RR}$ overexpression increased the phosphorylation of AKT, ERK1/2, and mammalian target of rapamycin (mTOR) and elevated the level of NF-kB; however, (P) RR silencing downregulated the expression of ERK1/2, AKT and NF-кB [32] in pancreatic cancer cells. Taken together, these findings indicate that (P) RR may contribute to cancer development through the MAPK/ERK and PI3K/AKT/mTOR pathways (Fig. 3).

\section{The V-ATPase}

The V-ATPase actively transfers protons into vesicles including lysosomes, endosomes and autophagosomes, by consuming energy acquired by the hydrolysis of
ATP to ADP, thus acting as a proton pump that is essential for cellular acidification [8]. The V-ATPase is also functionally expressed on the cell membranes of several types of human tumor cells such as promyelocytic leukaemia HL-60 cells and leiomyosarcoma cells [33, 34] as well as breast cancer cells [35]. In addition, bafilomycin A1, an inhibitor of V-ATPase activity, blocked the autophagy and growth of breast carcinoma cells [35]. Moreover, the expression of VATPases was elevated in cisplatin-resistant cell lines derived from various human cancer cells [36]. Notably, a truncated, transmembrane portion of (P) RR has been revealed to be associated with V-ATPase function [37]. In addition, Wnt binding stimulates the endocytosis of the signaling complex (including Wnts, Frizzled, LRP6, (P) RR, and the V-ATPase). The VATPase, via interaction with $(\mathrm{P}) \mathrm{RR}$, then generates a proton gradient across the vesicle membrane that is crucial for LRP6 phosphorylation and subsequent $\beta$ catenin activation [37]. These findings suggest that 
(P) RR might function in cancer promotion by acting synergistically with the V-ATPase (Fig. 3).

\section{Roles of $(P)$ RR in various cancers PDAC}

Recently, (P) RR has been demonstrated to play a pivotal role in the pathogenesis of PDAC. Shibayama et al. [11] demonstrated that compared with normal matched pancreatic tissues, premalignant pancreatic intraepithelial neoplasia (PanIN) and PDAC lesions exhibited aberrant (P) RR overexpression. Furthermore, (P) RR was revealed to be essential for $\mathrm{Wnt} / \mathrm{\beta}$-catenin-mediated proliferation of PDAC cells, while (P) RR silencing decreased Wnt signaling activity and cell proliferation, as well as induced the apoptosis of PDAC cells via caspase-3 activation [11]. Additionally, (P) RR expression was higher in human PDAC cell lines compared to that in normal pancreatic epithelial cells [11].To further analyze related information in big data, we have compared the levels of ATP6AP2 transcripts in tumor tissues of pancreatic adenocarcinoma (PAAD) and normal pancreatic tissues, based on the data provided in the TCGA and GTEx databases. In consistence with previous reports, we found that ATP6AP2 expression is significantly higher in tumor tissues than that in normal tissues $(P<0.01)$, moreover, level of ATP6AP2 expression in PAAD is positively correlated with the expression level of CTNNB1 ( $\beta$-catenin encoding gene) and Wnt target gene AXIN2 (Fig. 4a). Soon after the finding of Shibayama et al., (P) RR was further definitively identified as a potential molecular biomarker for the diagnosis of PDAC by Arundhathi et al. [32], who showed that (P) RR mRNA level was positively correlated with TNM stage in human PDAC (patient number $=90, r=0.688, P<0.001$ ) [32]. Moreover, anti-(P) RR antibody labelled with iodine-125 $\left({ }^{125} \mathrm{I}\right)$ is a promising tracer for imaging diagnosis by singlephoton emission computed tomography (SPECT)/CT in early stages of pancreatic cancer [32]. These findings revealed the essential roles of (P) RR in the molecular diagnosis and severity evaluation of pancreatic cancer.

\section{Glioma}

Kouchi et al. [13] reported that aberrant (P) RR overexpression was observed in WHO grade II-IV gliomas independent of IDH1 R132H mutation. Moreover, by detecting the tissue samples of 31 patients, they found that the (P) RR expression level was positively correlated with the WHO grade and Ki-67 labelling index $(\mathrm{r}=0.8080, P<$ 0.0001 ), and negatively associated with the glioma patients' survival times $(r=-0.6499, P<0.0002)$ [13]. At the cellular level, (P) RR promoted the proliferation of human glioma cells through the Wnt/B-catenin pathway and inhibited cell apoptosis by attenuating caspase- 3 activation [13]. Consistent with these findings, Juillerat-Jeanneret et al. [38] also reported a high expression level of (P) RR in human glioblastoma (GBM) (WHO grade IV), the most malignant type of glioma [39], and indicated that attenuation of renin activity in glioblastoma cells could decrease cell proliferation and induce apoptosis. To further analyze related information in big data, we have compared the levels of ATP6AP2 transcripts in tumor tissues of GBM and normal matched tissues, based on the data provided in the TCGA and GTEx databases. In agreement with previous findings, we found that ATP6AP2 expression is higher in tumor tissues than that in normal tissues, moreover, level of $A T P 6 A P 2$ expression in GBM is positively correlated with those of CTNNB1, CCND1 and AGT (Fig. $4 \mathrm{~b})$. These findings suggest that (P) RR may contribute to glioma development through both Wnt signaling and the RAS signaling.

\section{CRC}

More than $80 \%$ of colorectal tumors harbor loss-offunction mutations in APC, and approximately $5 \%$ harbor activating mutation in $\beta$-catenin $[40,41]$, which result in constitutive aberrant activation of the $\mathrm{Wnt} / \beta$-catenin pathway and thus promote carcinogenesis [42]. Interestingly, Voloshanenko et al. [43] found that Wnt3 knockdown noticeably reduced the activity of the $\mathrm{Wnt} / \mathrm{\beta}$ catenin pathway and proliferation of CRC cells independent of APC or $\beta$-catenin mutations. The above findings suggest that Wnts can further stimulate a mutated Wnt/ $\beta$-catenin pathway with constitutively hyperactivated signaling activity. More recently, we have published the data that demonstrated, for the first time, that $(\mathrm{P}) \mathrm{RR}$ promotes CRC through the Wnt/ $\beta$-catenin pathway despite constitutive activating mutations in APC or $\beta$-catenin [10]. To further verify those results in big data, we have compared the levels of ATP6AP2 transcripts in tumor tissues of colon adenocarcinoma (COAD) and normal matched tissues, based on the data in the TCGA and GTEx databases. In consistence with our previous findings, the results showed that ATP6AP2 expression is higher in tumor tissues than that in normal tissues, moreover, level of ATP6AP2 transcripts in COAD is positively correlated with those of LRP6, CTNNB1, MYC, CCND1 and AXIN2 (Fig. 4c). In addition, we further summarized the relationship between (P) RR expression levels, detected through the immunohistochemistry and evaluated by 3 independent pathologists as previously described [10], in primary tumor tissues and a series of detailed pathophysiological characteristics of $60 \mathrm{CRC}$ patients (information collected from Kagawa University Hospital, Japan). We found that higher (P) RR expression levels are more commonly observed in patients with the following characteristics: male sex, early age at onset, poorly differentiated lesions, advanced cancer stage, distant metastasis, rapid progression, lower 5-year survival rate and shorter recurrence-free 


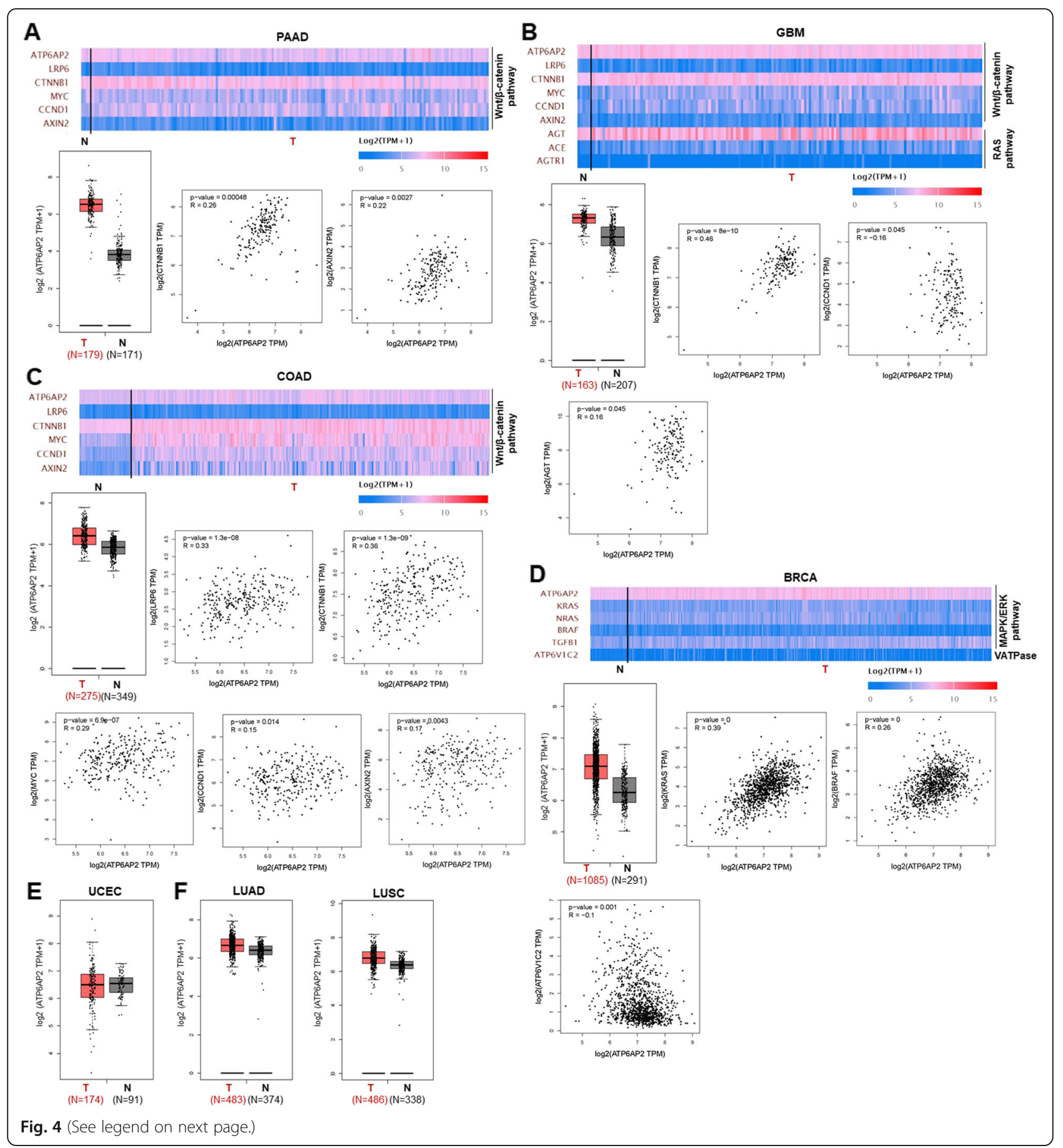






survival time (Table 1). Recently, Maider et al. [44] reported their latest data which are highly consistent with our previous findings. In their study, (P) RR protein levels were detected in tissues of adenomatous polyps and cancers from the same CRC patients $(n=42)$, as well as in tissues of primary tumors and nodal and liver metastases from advanced CRC patients $(n=294)$ [44]. The results showed that (P) RR expression increases throughout the colorectal adenoma-adenocarcinoma process, moreover, (P) RR protein in both primary tumor and distant metastases is associated with worse prognosis including 5- and 10-year survival of CRC patients [44].

Current therapeutic strategies for CRC are mainly limited to epidermal growth factor receptor (EGFR) monoclonal antibody-based treatment, which is focused on inhibiting the MAPK/ERK pathway (also called the EGFRRAS-RAF-MEK-ERK pathway) and thus attenuates cancer cell proliferation. However, approximately $30-50 \%$ of CRCs carry a KRAS mutation, which automatically activates the downstream pathway and results in resistance to EGFR-targeted therapy. Interestingly, the close interaction between the Wnt/ $/$-catenin and RAS-ERK pathways and the strong potential of anticancer strategies targeting Wnt signaling via the degradation of both $\beta$-catenin and RAS have been recognized [45]. Notably, Wang et al. [10] found that (P) RR silencing markedly inhibited the proliferation and induced the apoptosis of CRC cell lines carrying both activating mutations in Wnt signaling components and KRAS mutations DLD-1 (with APC and KRAS mutations) and HCT116 (with $\beta$-catenin and KRAS mutations) by weakening Wnt signaling activity. These findings suggest that (P) RR has great potential as a novel biomarker and therapeutic target for CRC despite spontaneously activating mutations in the Wnt/ $\beta$-catenin and/ or RAS-ERK pathways.

\section{Breast cancer}

Ohba et al. [14] previously indicated that ( $P$ ) RR expression was detected by immunohistochemistry in breast cancer cells in 50 of 69 cases $(72 \%)$ of breast carcinoma. Furthermore, the number of (P)RR-positive cases was much higher in the group with $\geq 10 \%$ Ki-67 (a cell proliferation marker) staining than in the group with $<10 \%$ Ki-67 staining. (P) RR silencing inhibited the proliferation of both MCF-7 (estrogen receptor (ER) $\alpha$-positive) and SK-BR-3 (ER $\alpha$-negative) breast cancer cells. By contrast, prorenin dose-dependently stimulated ERK1/2 phosphorylation in MCF-7 and SK-BR-3 cells [14]. Moreover, the proliferation of MCF-7 and SK-BR-3 cells was significantly decreased, to 32 and $44 \%$ that of the control cells, respectively, by treatment with $10 \mathrm{nM}$ bafilomycin A1, an inhibitor of the V-ATPase [14]. The above data suggest that $(\mathrm{P}) \mathrm{RR}$ may stimulate the proliferation of breast carcinoma cells, possibly via ERK $1 / 2$ phosphorylation and/or the association with the VATPase. We have also analyzed related information in the TCGA and GTEx databases. Consistently, we found that compared with normal matched tissues, the level of ATP6AP2 transcripts in tumor tissues of breast invasive carcinoma (BRCA) are obviously higher, moreover, level of ATP6AP2 expression in BRCA is positively correlated with those of the MAKP/ERK pathway components $K R A S$ and $B R A F$, as well as that of the V-ATPase encoding gene ATP6V1C2 (Fig. 4d). Therefore, (P) RR may contribute to the development of breast cancer through both the MAKP/ERK pathway and V-ATPase.

\section{Aldosterone-producing adenoma (APA)}

Recarti et al. [46] have detected high expression of (P) RR in APA tissues and HAC15 adrenocortical carcinoma cells that can produce aldosterone once treated with Ang II. Binding of prorenin and (P) RR could trigger the expression of the aldosterone synthase CYP11B2 and ERK1/2 phosphorylation, thus promoting the production and secretion of aldosterone [46]. Furthermore, Yamamoto et al. [15] revealed that both the mRNA and protein expression levels of (P) RR are elevated in tumor tissues of APAs relative to these levels in the matched non-neoplastic adrenal tissues and tissues from 
Table 1 Association between (P) RR expression levels in primary colorectal tumors and clinicopathological characteristics

\begin{tabular}{|c|c|c|c|c|c|c|}
\hline & \multirow[t]{3}{*}{$\begin{array}{l}\text { Case } \\
\text { number }\end{array}$} & \multicolumn{3}{|c|}{$\begin{array}{l}\text { (P) RR expression level } \\
\text { (Immunohistochemistry) }\end{array}$} & \multicolumn{2}{|c|}{$\begin{array}{l}\text { Constituent ratio } \\
\text { difference }\end{array}$} \\
\hline & & Weak & Middle & Strong & $P$ value & $x^{2}$ \\
\hline & & \multicolumn{3}{|c|}{ Case number (percentage) } & & \\
\hline Gender & 60 & & & & & \\
\hline Male & 31 & $4(12 \%)$ & $\begin{array}{l}15 \\
(47 \%)\end{array}$ & $\begin{array}{l}13 \\
(41 \%)\end{array}$ & $<0.0001^{* * *}$ & 27.36 \\
\hline Female & 28 & $9(32 \%)$ & $\begin{array}{l}16 \\
(57 \%)\end{array}$ & $\begin{array}{l}13 \\
(11 \%)\end{array}$ & & \\
\hline Onset age & 60 & & & & & \\
\hline$<60$ & 12 & $1(8 \%)$ & $7(59 \%)$ & $4(33 \%)$ & $0.005^{* *}$ & 10.6 \\
\hline$\geq 60$ & 48 & $\begin{array}{l}12 \\
(25 \%)\end{array}$ & $\begin{array}{l}24 \\
(50 \%)\end{array}$ & $\begin{array}{l}12 \\
(25 \%)\end{array}$ & & \\
\hline WHO Grade of cancer differentiation & 60 & & & & & \\
\hline Grade 1 & 17 & $5(29 \%)$ & $\begin{array}{l}11 \\
(65 \%)\end{array}$ & $1(6 \%)$ & $<0.0001^{* * *}$ & 77.56 \\
\hline Grade 2 & 30 & $7(23 \%)$ & $\begin{array}{l}16 \\
(53 \%)\end{array}$ & $7(23 \%)$ & & \\
\hline Grade 3 & 13 & $1(8 \%)$ & $4(31 \%)$ & $8(61 \%)$ & & \\
\hline UICC Stage & 60 & & & & & \\
\hline Stage II & 20 & $9(45 \%)$ & $8(40 \%)$ & $3(15 \%)$ & $<0.0001^{* * *}$ & 65.5 \\
\hline Stage III & 20 & $3(15 \%)$ & $\begin{array}{l}13 \\
(65 \%)\end{array}$ & $4(20 \%)$ & & \\
\hline Stage IV & 20 & $1(5 \%)$ & $\begin{array}{l}10 \\
(50 \%)\end{array}$ & $9(45 \%)$ & & \\
\hline Distant Metastasis and/or Progression after radical operation & 60 & & & & & \\
\hline No & 23 & $5(22 \%)$ & $\begin{array}{l}14 \\
(61 \%)\end{array}$ & $4(17 \%)$ & $0.0352^{*}$ & 6.695 \\
\hline Yes & 37 & $8(22 \%)$ & $\begin{array}{l}17 \\
(46 \%)\end{array}$ & $\begin{array}{l}12 \\
(32 \%)\end{array}$ & & \\
\hline $\begin{array}{l}\text { Five-year survival (patients who finished the } 5 \text {-year follow-up o } \\
5 \text { years) }\end{array}$ & 47 & & & & & \\
\hline Yes & 25 & $5(20 \%)$ & $\begin{array}{l}13 \\
(52 \%)\end{array}$ & $7(28 \%)$ & $\begin{array}{l}0.0358 \\
*\end{array}$ & 6.661 \\
\hline No & 22 & $2(9 \%)$ & $\begin{array}{l}11 \\
(50 \%)\end{array}$ & $9(41 \%)$ & & \\
\hline $\begin{array}{l}\text { Recurrence-free survival time (duration from radical operation } \\
\text { (20 cases who had recurrence after radical operation) }\end{array}$ & (months) & & & & & \\
\hline (P) RR expression level & & & $P$ value & $x^{2}$ & $\begin{array}{l}\text { Hazard } \\
\text { radio }\end{array}$ & $95 \% \mathrm{Cl}$ \\
\hline $\begin{array}{l}\text { Week/Middle } \\
\text { (16 cases) }\end{array}$ & $\begin{array}{l}\text { Strong } \\
\text { (4 cases) }\end{array}$ & & & & & \\
\hline 10.4 & 5.85 & & $0.0064 * *$ & 7.438 & 0.06804 & $\begin{array}{l}0.00986- \\
0.4695\end{array}$ \\
\hline
\end{tabular}

UICC The Union for International Cancer Control

other adrenal tumors. These data suggest that (P) RR may play pivotal roles, such as promoting cell proliferation and aldosterone secretion, in APAs.

\section{Endometrial cancer}

Delforce et al. [28] revealed that a dysfunctional endometrial RAS aids the growth and spread of endometrial cancer. The protein and mRNA levels of RAS components in 30 human endometrial carcinomas and their corresponding adjacent endometrial tissues were measured, and data showed that protein levels of $(\mathrm{P}) \mathrm{RR}$ and the mRNA levels of (P) RR, AGTR1, ACE1 and ACE2 were significantly higher in the tumor tissues than those in the matched normal endometrial tissues $(P=0.023$, 
$0.008,0.004$ and 0.046 , respectively) [28]. TGF $\beta 1$, a target of the endometrial RAS, was closely associated with RAS component expression and was upregulated in tumor tissues $(P=0.001)$ [28]. These data suggest that (P) RR possibly contributes to endometrial cancer by enhancing activity in the RAS. In addition, Lumbers et al. [47] further indicated that endometrial (P)RR/RAS system can be up-regulated by decidualization, increased prorenin will then stimulate the expression and secretion of vascular endothelial growth factor (VEGF), which could be important to establish an abundant blood supply for cancer development. However, there is a paradox when we analyzed related data in the TCGA and GTEx databases. Different from the findings of the above study, big data analysis showed that ATP6AP2 transcripts in tumor tissues of uterine corpus endometrial carcinoma (UCEC) is at similar level to that of the matched normal tissues (Fig. 4e). Therefore, further study with larger sample number and further analysis of stratified samples are needed to explicit whether $(\mathrm{P}) \mathrm{RR}$ indeed play a role in the pathogenetic process of endometrial cancer.

\section{Lung cancer}

Goldstein et al. [48] analyzed the data of lung cancer patients provided by the Gene Expression Omnibus (GEO) database (tumor: $n=57$; normal tissue: $n=49$ ) and found no significant difference in the ATP6AP2 gene expression level between normal and lung cancer tissues. We have analyzed related information in the TCGA and GTEx databases and found that the ATP6AP2 transcripts in tumor tissues of either lung adenocarcinoma (LUAD) or lung squamous cell carcinoma (LUSC) are slightly higher than those of the corresponding normal tissues (Fig. 4f). These findings suggest that $(\mathrm{P}) \mathrm{RR}$ may not contribute much to lung cancer carcinogenesis.
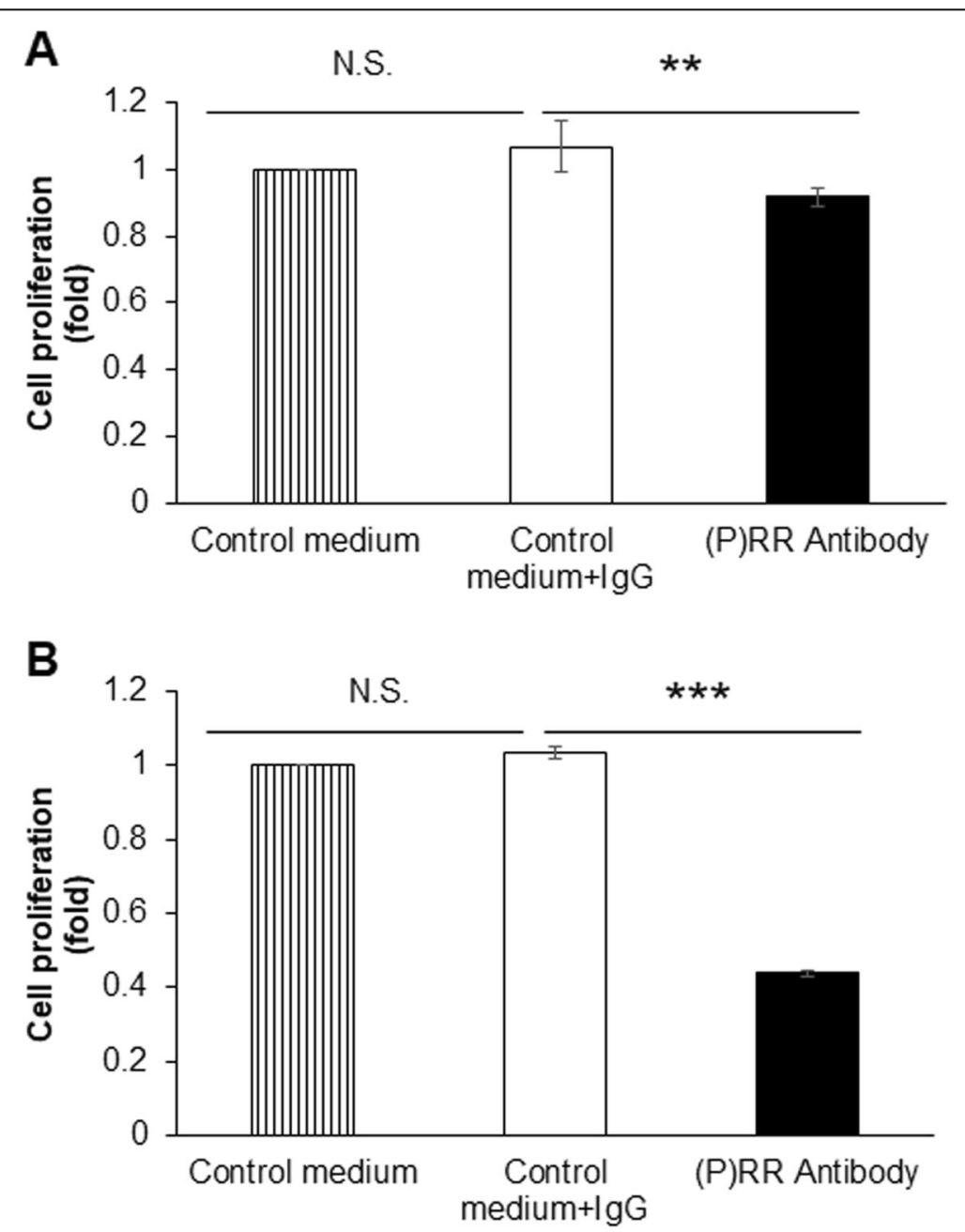

Fig. 5 (P) RR inhibition attenuates the proliferation of CRC cells in vitro. a and $\mathbf{b}$ Treatment with (P) RR antibody for $48 \mathrm{~h}$ markedly inhibited the proliferation of DLD-1 (a) and HCT116 (b) cells, as measured by a WST-1 assay. The data are expressed as relative values compared to the vehicletreated group. N.S.: not significant. ${ }^{* *} P<0.01 .{ }^{* *} P<0.001 . n=4$ 
Future perspectives: applications in diagnosis and targeting

\section{Plasma $s(P) R R$ : aiding the prediction of cancer initiation and progression}

Shibayama et al. [11] indicated that plasma $s(P) R R$ levels in patients with PDAC are higher than those in healthy controls and that cultured human PDAC cell lines showed dramatically higher levels of $s(P) R R$ secretion than normal pancreatic epithelial cells, indicating that plasma $s(\mathrm{P}) \mathrm{RR}$ can be a potential and promising predictive biomarker for PDAC. However, the predictive value of plasmatic $s(P) R R$ in CRC and primary epithelial ovarian cancer (EOC) seems not that obvious. Maider et al. [44] collected plasma from 161 patients with CRC followed by the measurement of $s(P) R R$, as a result, they found that plasmatic $s(\mathrm{P}) \mathrm{RR}$ of CRC patients were at similar level to that of healthy controls and was not associated with disease progression. Additionally, Katrin et al. [49] tested s(P) RR in the plasma of 197 patients with primary EOC, analyzed the potential association between plasmatic $\mathrm{s}(\mathrm{P}) \mathrm{RR}$ and clinicopathological outcome of the patients, as well as compared levels of plasmatic $s(\mathrm{P}) \mathrm{RR}$ of the patients and healthy controls. The results showed no correlation between $s(\mathrm{P}) \mathrm{RR}$ level and clinicopathological characteristics of EOC including stage, grade and chemotherapy response, no association between $\mathrm{s}(\mathrm{P}) \quad \mathrm{RR}$ level and prognostic parameters including overall survival and progression-free survival of patients, and no difference of $s(P) R R$ level between patients and healthy controls [49]. In short, s(P) RR showed no predictive, prognostic, or diagnostic value in EOC. Hence, the indicative value of $s(P) R R$ varies depend on different kinds of cancers. Therefore, future studies are needed to clarify whether plasma $s(P) R R$ is also valuable in other kinds of cancers as a biomarker for early prediction, therapeutic evaluation and prognosis assessment. Notably, an s(P) RR ELISA kit has been developed to detect $s(\mathrm{P}) \mathrm{RR}$ in blood and urine samples [50]. By using this assay, increased serum s(P) RR levels have been detected in patients with various diseases, including heart failure [51], kidney disease [52, 53], hypertension [54], and preeclampsia [55]. These results indicate the great feasibility of measuring plasma $s(P)$ $\mathrm{RR}$ as a predictive biomarker in certain kinds of cancers.

\section{Tumor tissue ( $P$ ) RR expression: aiding cancer diagnosis, severity evaluation and prognosis prediction}

Since the (P) RR expression levels in tumor tissues are closely correlated with the grades and stages of various cancers, (P) RR expression may serve as an adjuvant marker, in combination with current cancer-related protein markers, to aid diagnosing as well as evaluating the severity of and predicting the prognosis of various cancers.

Table 2 Studies investigating the roles of (P) RR in different cancers

\begin{tabular}{|c|c|c|c|c|}
\hline Study & Tumor type & $\begin{array}{l}\text { Cancer cell line } \\
\text { (human) }\end{array}$ & $\begin{array}{l}\text { (P)RR-Related } \\
\text { pathway or factor }\end{array}$ & Finding \\
\hline $\begin{array}{l}\text { Shibayama } \\
\text { et al., } 2015[11]\end{array}$ & $\begin{array}{l}\text { Pancreatic ductal } \\
\text { adenocarcinoma } \\
\text { (PDAC) }\end{array}$ & $\begin{array}{l}\text { PK-8, PCl-35, BxPC-3, } \\
\text { PK-1, PANC-1 and } \\
\text { MIAPaCa-2 }\end{array}$ & $\begin{array}{l}\text { Wnt/ } \beta \text {-catenin } \\
\text { pathway }\end{array}$ & $\begin{array}{l}\text { Higher (P) RR expression: higher proliferation ability and less } \\
\text { apoptosis of cancer cells; enhanced Wnt/ } \beta \text {-catenin activity }\end{array}$ \\
\hline $\begin{array}{l}\text { Arundhathi } \\
\text { et al., } 2016 \text { [32] }\end{array}$ & PDAC & $\begin{array}{l}\text { Panc-1, ASPC, BXPC-3, } \\
\text { HPAC, and MIAPaCa-2 }\end{array}$ & $\begin{array}{l}\text { MAPK/ERK and } \\
\text { PI3K/AKT/mTOR } \\
\text { pathways }\end{array}$ & $\begin{array}{l}\text { Higher (P) RR expression: more advanced disease; enhanced } \\
\text { MAPKJERK and PI3K/AKT/mTOR signaling activity }\end{array}$ \\
\hline $\begin{array}{l}\text { Kouchi et al., } \\
2017 \text { [13] }\end{array}$ & Glioma & $\begin{array}{l}\text { U251MG, U87MG, and } \\
\text { T98G }\end{array}$ & $\begin{array}{l}\text { Wnt/ } \beta \text {-catenin } \\
\text { pathway }\end{array}$ & $\begin{array}{l}\text { Higher (P) RR expression: more advanced disease; higher } \\
\text { proliferation ability and less apoptosis of cancer cells; enhanced } \\
\text { Wnt/ } \beta \text {-catenin activity }\end{array}$ \\
\hline $\begin{array}{l}\text { Juillerat- } \\
\text { Jeanneret } \\
\text { et al., } 2004 \text { [38] }\end{array}$ & $\begin{array}{l}\text { Glioblastoma } \\
\text { (GBM) }\end{array}$ & LN18 and LNZ308 & RAS pathway & $\begin{array}{l}\text { Higher (P) RR expression: more advanced disease; higher } \\
\text { proliferation ability of cancer cells; enhanced RAS activity }\end{array}$ \\
\hline $\begin{array}{l}\text { Wang et al., } \\
2019 \text { [10] }\end{array}$ & $\begin{array}{l}\text { Colorectal cancer } \\
(\mathrm{CRC})\end{array}$ & DLD-1 and HCT116 & $\begin{array}{l}\text { Wnt/ } \beta \text {-catenin } \\
\text { pathway }\end{array}$ & $\begin{array}{l}\text { Higher (P) RR expression: higher proliferation ability and less } \\
\text { apoptosis of cancer cells; enhanced Wnt/ } \beta \text {-catenin activity }\end{array}$ \\
\hline $\begin{array}{l}\text { Maider et al., } \\
2019 \text { [44] }\end{array}$ & CRC & $\begin{array}{l}\text { Not applicable (only } \\
\text { clinical samples were } \\
\text { used) }\end{array}$ & Not applicable & $\begin{array}{l}\text { Higher (P) RR expression: more advanced disease; worse } \\
\text { prognosis (e.g. 5- or 10- year survival) }\end{array}$ \\
\hline $\begin{array}{l}\text { Ohba et al., } \\
2014[14]\end{array}$ & Breast cancer & $\begin{array}{l}\text { MCF-7, T47D, SK-BR-3 } \\
\text { and MDA-MB-231 }\end{array}$ & $\begin{array}{l}\text { MAKP/ERK } \\
\text { pathway and V- } \\
\text { ATPase }\end{array}$ & $\begin{array}{l}\text { Higher (P) RR expression: higher proliferation ability of cancer } \\
\text { cells }\end{array}$ \\
\hline $\begin{array}{l}\text { Yamamoto } \\
\text { et al., } 2013 \text { [15] }\end{array}$ & $\begin{array}{l}\text { Aldosterone- } \\
\text { producing } \\
\text { adenoma (APA) }\end{array}$ & H295R and HAC15 & Not mentioned & $\begin{array}{l}\text { Higher (P) RR expression: higher proliferation ability of cancer } \\
\text { cells and more aldosterone secretion }\end{array}$ \\
\hline $\begin{array}{l}\text { Delforce et al., } \\
2017 \text { [28] }\end{array}$ & Endometrial cancer & MCF-7 & RAS & $\begin{array}{l}\text { Higher (P) RR expression: higher proliferation ability of cancer } \\
\text { cells, possibility of cancer spread and RAS activity }\end{array}$ \\
\hline
\end{tabular}




\section{Anti-(P) RR antibodies}

Since (P) RR intensely promotes many kinds of cancers, overcoming cancers with anti-(P) RR monoclonal antibodies should be very promising. We have generated a monoclonal antibody against (P) RR targeted to the region spanning amino acids 200 to 213 in the extracellular domain of (P) RR and then confirmed its specificity and quality, in a way described previously [56]. To assess the effect of this antibody, human CRC DLD-1 and HCT116 cells, purchased from the American Type Culture Collection (ATCC; Manassas, VA, USA), were seeded into 24-well plates at a density of $2 \times 10$ [4] cells/ well. After the cells grew to approximately $40 \%$ confluence, they were serum-starved for $24 \mathrm{~h}$ without antibiotics and were then treated with either the monoclonal (P) RR antibody or human IgG (Thermo Fisher Scientific, catalogue \#31154) as the negative control at a concentration of $200 \mu \mathrm{g} / \mathrm{mL}$ ( $500 \mu \mathrm{L}$ of solution per well). After treatment for $48 \mathrm{~h}$, cell proliferation activity was assessed by a water-soluble tetrazolium salt (WST)-1 assay, as previously described [10]. The WST-1 assay data indicated that cell proliferation was consistently attenuated by blocking the specific amino acid regions on the extracellular domain of $(\mathrm{P}) \mathrm{RR}$ with the monoclonal antibody. Compared with treatment with human IgG, treatment with the (P) RR antibody for $48 \mathrm{~h}$ markedly decreased the proliferation of both DLD-1 (mean \pm SEM; $1.07 \pm 0.08$ vs. $0.92 \pm 0.03$, relative ratio compared to the vehicle group without antibody treatment; $P<0.01$ ) (Fig. 5a) and HCT116 (mean \pm SEM; $1.04 \pm 0.02$ vs. $0.44 \pm 0.01$, relative ratio compared to the vehicle group; $P<0.001$ ) cells (Fig. 5b). These data revealed the promising potential anti-colon cancer effect of the $(P) R R$ antibody, and further studies on (P) RR antibodies are ongoing.

\section{Conclusions}

Overexpression of $(\mathrm{P}) \mathrm{RR}$, which may contribute to cancer initiation and progression via the $\mathrm{Wnt} / \beta$-catenin, RAS, MAPK/ERK and PI3K/AKT/mTOR pathways as well as V-ATPase function, has been observed in various cancers including pancreatic, brain, colorectal, endometrial, breast and adrenal cancers (Table 2). Since multiple functions of (P) RR play important roles in cancer pathophysiology, alternative pathways will also be identified in the future. Taken together, these findings indicate that $(\mathrm{P}) \mathrm{RR}$, including the full-length form in tumor tissues and the soluble form in the blood, has substantial potential as a novel biomarker for cancer diagnosis, severity evaluation and prognosis prediction and is also a promising therapeutic target for cancers. Therefore, $(\mathrm{P})$ RR monoclonal antibodies, which are in development and testing, will play essential roles in cancer treatment in the future.

\begin{abstract}
Abbreviations
(P)RR: (pro) renin receptor; ACE: angiotensin-converting enzyme;

AGT: angiotensinogen; AGTR: Ang II/Ang II receptor; Ang: angiotensin; APC: Adenomatous polyposis coli; Axin: axis inhibition protein; CCND1: cyclin D1; COAD: colon adenocarcinoma; CRC: colorectal cancer; CTNNB1: catenin beta 1; DLBC: lymphoid neoplasm diffuse large B-cell Lymphoma; EMT: epithelial-to-mesenchymal transition; EOC: epithelial ovarian cancer; ERK: extracellular signal-regulated kinases; ERK1/2: extracellular signalregulated kinase 1/2; FL(P)RR: full-length (P)RR; GBM: glioblastoma; GEO: Gene Expression Omnibus; GSK3: Glycogen synthase kinase 3; GTEx: Genotype-Tissue Expression; KIRC: kidney renal clear cell carcinoma; LEF: lymphoid enhancer-binding factor; LRP6: low-density lipoprotein receptor protein 6; LUAD: lung adenocarcinoma; LUSC: lung squamous cell carcinoma; MAPK: mitogen-activated protein kinase; mTOR: mammalian target of rapamycin; PAAD: pancreatic adenocarcinoma; PAAD: pancreatic adenocarcinoma; PanIN: pancreatic intraepithelial neoplasia;

PDAC: pancreatic ductal adenocarcinoma; RAS: renin-angiotensin system; ROS: reactive oxygen species; s(P)RR: soluble (P)RR; SPECT: single-photon emission computed tomography; STAD: stomach adenocarcinoma; TCF: Tcell factor; TCGA: Cancer Genome Atlas; TGCT: testicular germ cell tumors; TGF: transforming growth factor; THYM: thymoma; UCEC: uterine corpus endometrial carcinoma; V-ATPase: vacuolar H + -ATPase; VEGF: vascular endothelial growth factor; WST: water-soluble tetrazolium salt
\end{abstract}

\section{Acknowledgements \\ We sincerely acknowledge the generous support by the Japanese Society for the Promotion of Science Grants-in-Aid for Scientific Research, Hoansha Foun- dation of Japan, Fundamental Research Funds for the Central Universities of China and National Natural Science Foundation of China. This study was par- tially supported by the Japanese Society for the Promotion of Science Grants- in-Aid for Scientific Research (KAKENHI: $18 \mathrm{H} 03191$ to A. N.) and Hoansha Foun- dation of Japan (to A. N.). This work was also supported by Fundamental Re- search Funds for the Central Universities of China (No. 2019FZJD009 to J. W.) and grants from the National Natural Science Foundation of China (No. 81902956 to J. W., No. 81872481 to Y. Y. and No. 81872101 to Z. W.).}

\section{Authors' contributions}

JW collected the related paper and drafted the manuscript. MM produced the (P) RR monoclonal antibody. YY, AN and ZW participated in the design of the review, draft and revised the manuscript. All authors read and approved the final manuscript.

\section{Availability of data and materials}

The material supporting the conclusion of this review has been included within the article.

\section{Ethics approval and consent to participate}

All research activities for this article were in accordance with the Declaration of Helsinki and approved by the Ethics Committee of Kagawa University. Colon tissue samples were provided by Kagawa University Hospital. Signed informed consents were provided.

\section{Consent for publication}

Not applicable.

\section{Competing interests}

The authors declare no conflicts of interest.

\section{Author details}

${ }^{1}$ Department of Medical Oncology, The Second Affiliated Hospital of Zhejiang University School of Medicine, Hangzhou, China. ${ }^{2}$ Cancer Institute (Key Laboratory of Cancer Prevention and Intervention, China National Ministry of Education), The Second Affiliated Hospital, Zhejiang University School of Medicine, 88 Jiefang Road, Hangzhou 310009, China. ${ }^{3}$ Department of Pharmacology, Faculty of Medicine, Kagawa University, Kagawa, Japan. ${ }^{4}$ Division of Molecular Genetics, Shigei Medical Research Institute, Okayama, Japan. ${ }^{5}$ Department of Immuno-oncology, Fourth Affiliated Hospital of Hebei Medical University, Shijiazhuang, China. 
Received: 17 December 2019 Accepted: 5 February 2020

\section{10.0}

\section{References}

1. Nguyen G, Delarue F, Burckle C, Bouzhir L, Giller T, Sraer JD. Pivotal role of the renin/prorenin receptor in angiotensin II production and cellular responses to renin. J Clin Invest. 2002;109(11):1417-27.

2. Burckle C, Bader M. Prorenin and its ancient receptor. Hypertension. 2006; 48(4):549-51.

3. Cruciat CM, Ohkawara B, Acebron SP, Karaulanov E, Reinhard C, Ingelfinger $D$, et al. Requirement of prorenin receptor and vacuolar H+-ATPasemediated acidification for Wnt signaling. Science. 2010;327(5964):459-63.

4. Ichihara A, Sakoda M, Kurauchi-Mito A, Kaneshiro Y, Itoh H. Renin, prorenin and the kidney: a new chapter in an old saga. J Nephrol. 2009;22(3):306-11.

5. Schroten NF, Gaillard CA, van Veldhuisen DJ, Szymanski MK, Hillege HL, de Boer RA. New roles for renin and prorenin in heart failure and cardiorenal crosstalk. Heart Fail Rev. 2012;17(2):191-201.

6. Huang Y, Wongamorntham S, Kasting J, McQuillan D, Owens RT, Yu L, et al. Renin increases mesangial cell transforming growth factor-beta1 and matrix proteins through receptor-mediated, angiotensin II-independent mechanisms. Kidney Int. 2006;69(1):105-13.

7. Huang Y, Noble NA, Zhang J, Xu C, Border WA. Renin-stimulated TGF-beta1 expression is regulated by a mitogen-activated protein kinase in mesangial cells. Kidney Int. 2007;72(1):45-52.

8. Kinouchi K, Ichihara A, Sano M, Sun-Wada GH, Wada Y, Ochi H, et al. The role of individual domains and the significance of shedding of ATP6AP2/ (pro) renin receptor in vacuolar H(+)-ATPase biogenesis. PLoS One. 2013; 8(11):e78603.

9. Polakis P. Wnt signaling in cancer. Cold Spring Harb Perspect Biol 2012; 4 (5).

10. Wang J, Shibayama Y, Zhang A, Ohsaki H, Asano E, Suzuki Y, et al. (pro) renin receptor promotes colorectal cancer through the Wnt/beta-catenin signalling pathway despite constitutive pathway component mutations. Br J Cancer. 2019;120(2):229-37

11. Shibayama Y, Fujimori T, Nguyen G, Hirose T, Totsune K, Ichihara A et al. (Pro) renin receptor is crucial for Wnt/beta-catenin-dependent genesis of pancreatic ductal adenocarcinoma. Sci Rep 2015; 5: 8854

12. Arundhathi A, Chuang WH, Chen JK, Wang SE, Shyr YM, Chen JY, et al. Prorenin receptor acts as a potential molecular target for pancreatic ductal adenocarcinoma diagnosis. Oncotarget. 2016.

13. Kouchi M, Shibayama Y, Ogawa D, Miyake K, Nishiyama A, Tamiya T. (pro) renin receptor is crucial for glioma development via the Wnt/beta-catenin signaling pathway. J Neurosurg. 2017;127(4):819-28.

14. Ohba K, Suzuki T, Nishiyama H, Kaneko K, Hirose T, Totsune K, et al. Expression of (pro) renin receptor in breast cancers and its effect on cancercell proliferation. Biomed Res. 2014:35(2):117-26.

15. Yamamoto H, Kaneko K, Ohba K, Morimoto R, Hirose T, Satoh F, et al. Increased expression of (pro) renin receptor in aldosterone-producing adenomas. Peptides. 2013;49:68-73

16. Cousin C, Bracquart D, Contrepas A, Corvol P, Muller L, Nguyen G. Soluble form of the (pro) renin receptor generated by intracellular cleavage by furin is secreted in plasma. Hypertension. 2009:53(6):1077-82.

17. Yoshikawa A, Aizaki Y, Kusano K, Kishi F, Susumu T, lida S, et al. The (pro) renin receptor is cleaved by ADAM19 in the Golgi leading to its secretion into extracellular space. Hypertens Res. 2011;34(5):599-605.

18. Ludwig J, Kerscher S, Brandt U, Pfeiffer K, Getlawi F, Apps DK, et al. Identification and characterization of a novel 9.2-kDa membrane sectorassociated protein of vacuolar proton-ATPase from chromaffin granules. J Biol Chem. 1998;273(18):10939-47.

19. de Sousa EM, Vermeulen L, Richel D, Medema JP. Targeting Wnt signaling in colon cancer stem cells. Clin Cancer Res. 2011;17(4):647-53.

20. Kurayoshi M, Oue N, Yamamoto H, Kishida M, Inoue A, Asahara T, et al. Expression of Wnt-5a is correlated with aggressiveness of gastric cancer by stimulating cell migration and invasion. Cancer Res. 2006;66(21):10439-48.

21. Gupta S, Iljin K, Sara H, Mpindi JP, Mirtti T, Vainio P, et al. FZD4 as a mediator of ERG oncogene-induced WNT signaling and epithelial-tomesenchymal transition in human prostate cancer cells. Cancer Res. 2010; 70(17):6735-45.

22. Howe LR, Brown AM. Wnt signaling and breast cancer. Cancer Biol Ther. 2004;3(1):36-41.
23. El Wakil A, Lalli E. The Wnt/beta-catenin pathway in adrenocortical development and cancer. Mol Cell Endocrinol. 2011;332(1-2):32-7.

24. Klaus A, Birchmeier W. Wnt signalling and its impact on development and cancer. Nat Rev Cancer. 2008:8(5):387-98.

25. Lin CM, Chen HH, Lin CA, Wu HC, Sheu JJ, Chen HJ. Apigenin-induced lysosomal degradation of beta-catenin in Wnt/beta-catenin signaling. Sci Rep. 2017;7(1):372

26. He TC, Sparks AB, Rago C, Hermeking H, Zawel L, da Costa LT, et al. Identification of C-MYC as a target of the APC pathway. Science. 1998; 281(5382):1509-12.

27. George AJ, Thomas WG, Hannan RD. The renin-angiotensin system and cancer: old dog, new tricks. Nat Rev Cancer. 2010;10(11):745-59.

28. Delforce SJ, Lumbers ER. Corbisier de Meaultsart C, Wang Y, Proietto a, Otton $\mathrm{G}$ et al. expression of renin-angiotensin system (RAS) components in endometrial cancer. Endocr Connect. 2017:6(1):9-19.

29. Zavadil J, Bottinger EP. TGF-beta and epithelial-to-mesenchymal transitions. Oncogene. 2005;24(37):5764-74.

30. Krop M, Lu X, Danser AH, Meima ME. The (pro) renin receptor. A decade of research: what have we learned? Pflugers Arch. 2013;465(1):87-97.

31. Peng H, Li W, Seth DM, Nair AR, Francis J, Feng Y. (Pro) renin receptor mediates both angiotensin II-dependent and -independent oxidative stress in neuronal cells. PLoS One. 2013;8(3):e58339.

32. Arundhathi A, Chuang WH, Chen JK, Wang SE, Shyr YM, Chen JY, et al. Prorenin receptor acts as a potential molecular target for pancreatic ductal adenocarcinoma diagnosis. Oncotarget. 2016;7(34):55437-48.

33. Marquardt D, Center MS. Involvement of vacuolar $\mathrm{H}(+)$-adenosine triphosphatase activity in multidrug resistance in HL60 cells. J Natl Cancer Inst. 1991;83(15):1098-102.

34. Martinez-Zaguilan R, Lynch RM, Martinez GM, Gillies RJ. Vacuolar-type H(+ )-ATPases are functionally expressed in plasma membranes of human tumor cells. Am J Phys. 1993;265(4 Pt 1):C1015-29.

35. Sennoune SR, Bakunts K, Martinez GM, Chua-Tuan JL, Kebir Y, Attaya MN, et al. Vacuolar H+-ATPase in human breast cancer cells with distinct metastatic potential: distribution and functional activity. Am J Physiol Cell Physiol. 2004;286(6):C1443-52.

36. Murakami T, Shibuya I, Ise T, Chen ZS, Akiyama S, Nakagawa M, et al. Elevated expression of vacuolar proton pump genes and cellular $\mathrm{PH}$ in cisplatin resistance. Int J Cancer. 2001:93(6):869-74.

37. Nguyen G. Renin, (pro) renin and receptor: an update. Clin Sci (Lond). 2011; 120(5):169-78.

38. Juillerat-Jeanneret L, Celerier J, Chapuis Bernasconi C, Nguyen G, Wostl W, Maerki HP, et al. Renin and angiotensinogen expression and functions in growth and apoptosis of human glioblastoma. Br J Cancer. 2004;90(5):1059-68

39. Ohgaki H, Kleihues P. Genetic alterations and signaling pathways in the evolution of gliomas. Cancer Sci. 2009;100(12):2235-41.

40. Morin PJ, Sparks AB, Korinek V, Barker N, Clevers H, Vogelstein B, et al. Activation of beta-catenin-Tcf signaling in colon cancer by mutations in beta-catenin or APC. Science. 1997;275(5307):1787-90.

41. Comprehensive molecular characterization of human colon and rectal cancer. Nature 2012; 487 (7407): 330-337.

42. Reya T, Clevers H. Wnt signalling in stem cells and cancer. Nature. 2005; 434(7035):843-50

43. Voloshanenko O, Erdmann G, Dubash TD, Augustin I, Metzig M, Moffa G, et al. Wht secretion is required to maintain high levels of Wnt activity in colon cancer cells. Nat Commun. 2013:4:2610.

44. Beitia M, Solano-Iturri JD, Errarte P, Calvete-Candenas J, Loizate A, Etxezarraga MC et al. (Pro) renin Receptor Expression Increases throughout the Colorectal Adenoma-Adenocarcinoma Sequence and It is Associated with Worse Colorectal Cancer Prognosis. Cancers (Basel) 2019; 11 (6).

45. Jeong WJ, Ro EJ, Choi KY. Interaction between Wnt/beta-catenin and RASERK pathways and an anti-cancer strategy via degradations of beta-catenin and RAS by targeting the Wnt/beta-catenin pathway. NPJ Precis Oncol. 2018;2(1):5.

46. Recarti C, Seccia TM, Caroccia B, Gonzales-Campos A, Ceolotto G, Lenzini L, et al. Expression and functional role of the prorenin receptor in the human adrenocortical zona glomerulosa and in primary aldosteronism. J Hypertens. 2015;33(5):1014-22.

47. Lumbers ER, Wang Y, Delforce SJ, Corbisier de Meaultsart C, Logan PC, Mitchell MD, et al. Decidualisation of human endometrial stromal cells is associated with increased expression and secretion of prorenin. Reprod Biol Endocrinol. 2015;13:129. 
48. Goldstein B, Trivedi M, Speth RC. Alterations in gene expression of components of the renin-angiotensin system and its related enzymes in lung Cancer. Lung Cancer Int. 2017;2017:6914976.

49. Kreienbring K, Franz A, Richter R, Dragun D, Heidecke H, Dechend R, et al. Predictive and prognostic value of sPRR in patients with primary epithelial ovarian Cancer. Anal Cell Pathol (Amst). 2016;2016:6845213.

50. Maruyama N, Segawa T, Kinoshita N, Ichihara A. Novel sandwich ELISA for detecting the human soluble (pro) renin receptor. Front Biosci (Elite Ed) 2013; 5: 583-590.

51. Fukushima A, Kinugawa S, Homma T, Masaki Y, Furihata T, Abe T, et al. Increased plasma soluble (pro) renin receptor levels are correlated with renal dysfunction in patients with heart failure. Int J Cardiol. 2013;168(4): 4313-4

52. Hamada K, Taniguchi Y, Shimamura Y, Inoue K, Ogata K, Ishihara M, et al. Serum level of soluble (pro) renin receptor is modulated in chronic kidney disease. Clin Exp Nephrol. 2013;17(6):848-56.

53. Watanabe N, Morimoto S, Fujiwara T, Suzuki T, Taniguchi K, Mori F, et al. Prediction of gestational diabetes mellitus by soluble (pro) renin receptor during the first trimester. J Clin Endocrinol Metab. 2013;98(6):2528-35.

54. Morimoto S, Ando T, Niiyama M, Seki Y, Yoshida N, Watanabe D, et al. Serum soluble (pro) renin receptor levels in patients with essential hypertension. Hypertens Res. 2014;37(7):642-8.

55. Watanabe N, Bokuda K, Fujiwara T, Suzuki T, Mito A, Morimoto S, et al. Soluble (pro) renin receptor and blood pressure during pregnancy: a prospective cohort study. Hypertension. 2012;60(5):1250-6.

56. Sado $Y$, Inoue S, Tomono $Y$, Omori H. Lymphocytes from enlarged iliac lymph nodes as fusion partners for the production of monoclonal antibodies after a single tail base immunization attempt. Acta Histochem Cytochem. 2006;39(3):89-94.

\section{Publisher's Note}

Springer Nature remains neutral with regard to jurisdictional claims in published maps and institutional affiliations.

Ready to submit your research? Choose BMC and benefit from:

- fast, convenient online submission

- thorough peer review by experienced researchers in your field

- rapid publication on acceptance

- support for research data, including large and complex data types

- gold Open Access which fosters wider collaboration and increased citations

- maximum visibility for your research: over $100 \mathrm{M}$ website views per year

At $\mathrm{BMC}$, research is always in progress.

Learn more biomedcentral.com/submissions 